\title{
Friedreich's Ataxia in Northern Italy: I. Clinical, Neurophysiological and In Vivo Biochemical Studies
}

\author{
A. D'ANGELO, S. DI DONATO, G. NEGRI, F. BEULCHE, G. UZIEL and R. BOERI
}

\begin{abstract}
SUMMARY: Eighteen patients with the presumptive diagnosis of Friedreich's ataxia were studied. Clinical, neurophysiological and biochemical data were concordant in 14 patients and led to the diagnosis of typical Friedreich's ataxia in this group of patients. The remaining 4 patients differed from the typical patients in several respects, but mainly in the cardiological findings. It is concluded that no single clinical or laboratory finding is typical of F.A. Multidisciplinary approaches are essential to the diagnosis of Friedreich's ataxia.
\end{abstract}

RESUME: Nous avons étudié 18 patients avec le diagnostic présomptif d'ataxie de Friedreich. Chez 14 patients, les données cliniques, neurophysiologiques et biochimiques sont concordantes et conduisent au diagnostic de Friedreich typique; les 4 autres patients diffèrent des cas typiques de plusieurs facons, mais surtout par les résultats cardiologiques. Nous concluons qu'il n'existe pas encore de donnée clinique ou biochimique unique qui serait typique de l'ataxie de Friedreich. Il faut donc une approache multidisciplinaire.

From the Instituto Neurologico "C. Besta", Milano, Italy.

Reprint requests for the complete supplement on Friedreich's ataxia (Phase three) to: Dr. André Barbeau, Clinical Research Institute of Montreal, 110 Pine Ave. West, Montreal, Quebec, Canada H2W IR7.

\section{INTRODUCTION}

Friedreich's ataxia (F.A.) is a progressive multisystem degenerative disorder affecting the central and peripheral nervous system, bone and heart (Oppenheimer, 1958; Tyrer, 1975). The disorder is inherited in an autosomal recessive fashion and so is suitable for studies designed to identify the underlying genetic metabolic defect. In spite of the clinical and social importance of F.A. there has been no biochemical research in the field for many years. Recently, however, biochemical studies of Kark and Blass obtained in muscle biopsies from patients with degenerative disorders of the nervous system, provided new insights into the biology of F.A. (Kark et al, 1974). These extended studies, which lumped together several patients with ataxia and/or peripheral neuropathies, sought a single biochemical abnormality in biological material obtained from them. The results were consistent with a defect of pyruvate oxidation in several types of ataxia (Blass et al, 1970; 1976; Kark and Rodriquez-Budelli, 1979) and peripheral neuropathy (Kark et al, 1974; Williams, 1979). The Quebec Cooperative study group on F.A. (Barbeau, 1976; 1978; 1979) approached the subject differently. This group collected a number of patients with F.A. diagnosed according to strict clinical criteria (Geoffroy et al, 1976) and used a broad protocol of biochemical investigation (Barbeau, 1978). The Canadian team collected a large volume of data on the biology of the disease which led to a new hypothesis on the pathogenic mechanism of F.A., namely that the defects of pyruvate oxidation observed in patients were possibly a secondary effect of a major biochemical abnormality involving lipid metabolism (Barbeau, 1979; Huang et al, 1978). We decided to start a regional study of Friedreich's ataxia in patients selected according to strict clinical criteria for the following reasons: a) the complex nosology of spinocerebellar degeneration implies that ataxic phenotypes may not be related to the same genotypic and biochemical entity; b) ethical problems concerning the prognosis, treatment and family management of patients with F.A., strongly suggested that patients with pure F.A. should be separated from F.A. variants and from patients with other spinocerebellar degenerations. We therefore reviewed the patients previously admitted to the Instituto Neurologico with the diagnosis of spinocerebellar degeneration of Friedreich and applied to them a protocol of clinical, neurophysiological and in vivo biochemical studies in order to single out those with typical F.A. A biochemical study on cultured fibroblasts from these selected patients was subsequently performed. The results of the clinical, neurophysiological and in vivo biochemical studies are given here.

\section{MATERIALS AND METHODS}

Eighteen patients with the presumptive diagnosis of F.A. were available for the study. They were admitted to the Instituto Neurologico and were evaluated as follows: neurological signs and symptoms were, as far as possible, quantitated by means of the Mayo Clinic criteria. Each patient was videotaped for ataxic symptoms and degree of autonomy. Roentgenological evaluation consisted of standard skull, spine and chest films; CAT scanning was done in 11 of the 18 patients. Routine ophthalmological, otoneurological as well as a full cardiological evaluation consisting of electrocardiography (EKG), vectocardiography (VC), kinetocardiography (KC) and 
echocardiography (ECHO) were performed. The routine laboratory data are given under "Biochemical findings": 17 of the 18 patients and 17 agematched normal controls were subjected to a glucose-pyruvate tolerance test. $1.75 \mathrm{gr}$ of glucose $/ \mathrm{kg}$ body weight was diluted in water and given orally to the subjects fasted for 14 hours: blood glucose, pyruvate and lactate were determined at 0-30-60-90-120 and 180 minutes, as previously described $(\mathrm{Di}$ Donato et al, 1978). The pyruvate areas were evaluated in square $\mathrm{mm}$ (ordinate $0.1 \mathrm{mg}$ pyruvate $/ \mathrm{dl}=10 \mathrm{~mm}$; abscissa 10 minutes $=10 \mathrm{~mm}$ ). Serum lipoamide dehydrogenase was determined in parallel in 12 of the 18 patients ( 1 to 8 and 10 to 13 of table 1 ) and in 12 controls with a slightly modified version of the method of Pelley et al (1962). Practically, in a final volume of $400 \mu \mathrm{l}, 50 \mathrm{mM}$ Tris$\mathrm{HCl}$ buffer $\mathrm{pH} 7.8,3 \mathrm{mM}$ oxidized nicotinamide - adenine - dinucleotide $\left(\mathrm{NAD}^{+}\right), 5 \mathrm{mM}$ reduced lipoamide (reduced in 95\% ethanol with the use of $10 \mathrm{mM}$ dithiothreitol) were mixed with 20 or $40 \mu \mathrm{l}$ of fresh serum and the reduction of $\mathrm{NAD}^{+}$was followed at $30^{\circ} \mathrm{C}$ in a double-beam spectrophotometer at $340 \mathrm{~nm}$. The activities are expressed in $\mathrm{U} / \mathrm{l}$ (Pelley et al, 1962).

The electrophysiological study was carried out with 4 channel DISA (Model 1500) electromyograph. A standard electromyographic examination of the first dorsal interosseous (1 d.i.) tibialis anterior (t.a.) and extensor digitorum brevis (e.d.b.) muscles was performed with concentric needle electrodes, DISA 13 LOl. Maximal motor conduction velocities (VCMM) on the right ulnar (axillawrist) and left peroneal nerves were measured. Distal latencies were calculated on a standard distance of $6 \mathrm{~cm}$ between the stimulation and the recording points. Orthodromic sensory latencies were obtained from the right median nerve at the wrist (the stimulus was applied by a ring electrode, DISA $13 \mathrm{~L} 69$, on the third finger) and from the left sural nerve: pick-up electrodes were DISA $13 \mathrm{~K} 60$ surface electrodes. All the recordings were taken at a constant room temperature of $22 \pm$ $0.8^{\circ} \mathrm{C}$. Control values for electromyo- graphic and conduction velocity studies were obtained from a study performed in our laboratory in 170 age-matched normals.

\section{RESULTS \\ Clinical findings}

The results are summarized in table 1. Eleven females and 7 males were examined. Patients 8 and 9 (G.B. and G.M.), 15 and 16 (D.M. and D.R.), 17 and 18 (D.I. and D.W.) were siblings. Consanguinity of the parents was established for brothers 15 and 16 and sisters 17 and 18 (parents-first cousins). This was consistent with autosomal recessive inheritance of the disease. In the remaining 14 patients, the absence of vertical transmission of symptoms in the kinship argued for an autosomal recessive inheritance. The mean age at onset was 11 years (earliest onset in patient 5, 2 years; latest onset in patient 17, 22 years). All the patients except patient 9 had a history of progressive gait and limb ataxia and dysarthria. Physical examination of this 14 year-old-girl showed mild incoordination of the finger-nosefinger test, moderate deep sensory loss, absence of tendon reflexes, pes cavus, mild kyphoscoliosis and slight electrocardiographic signs of heart involvement (table 1). She was not conscious of any symptoms and lacked clear ataxic signs. This was attributed to the early stage of the disease.

Nystagmus was not a constant feature in the 18 patients. Tendon reflexes were absent in 16/18 of the patients: they were weak but still present in patients 14 and 16. Deep sensory loss was a feature in all patients except the two brothers 15 and 16. Babinski sign was present in all patients except patient 13 and the two sisters 17-18. Kyphoscoliosis was present in a moderate to severe degree in patients 1 to 13; it was present in mild degree in patients $14,15,16$ and absent in patients 17 and 18 . Pes cavus was present in all the patients except patient 7, 14 and 17. Symptoms and/or signs of cardiomyopathy (see Cardiological findings) were present in patients 1 to 14 but not in patients 15 to 18. These patients moreover, had neurological features additional to those found in the first group of patients ( 1 to 14): the two brothers 15 and 16 had fasciculations of the tongue, while the two sisters 17 and 18 had muscle cramps and myclonic jerks of the limbs. In the two sisters the onset of the first symptoms were delayed (age 20 and 22 respectively) and the progression of the disease had been slow. This was also true for patients 14 . The skull, spine and chest X-rays were significant in that they confirmed kyphoscoliosis and heart disease. CAT scanning was performed in patients 2 , $4,5,6,7,8,11,12,13,17,18$. It was normal in all except patient 2 in whom moderate cortical atrophy and slight enlargement of the lateral ventricles was found. Ophthalmological examination was negative. Otoneurological examination in 18 patients was consistent with moderate to severe vestibular cerebellar dysfunction, mainly evidenced by nystagmus and vestibular hyporeflexia to the caloric test.

\section{Cardiological findings}

In 14 patients ( 1 to 14) EKG showed moderate to severe anomalies of ventricular repolarization and in two $(8$ and 10$)$ signs of right ventricular hypertrophy. VC was consistent with the anomalies of ventricular repolarization in 9 patients $(1,2,5,6,8,10,12$, $13,14)$ and confirmed the right ventricular hypertrophy in patients 8 and 10. ECHO showed signs of septal asymmetric hypertrophy in 7 patients $(1,2,5,8,10,12,13)$ and signs of left concentric ventricular hypertrophy in $5(3,4,6,7$ and 11$) . \mathrm{KC}$ was rated abnormal in patients $1,2,5,8,10,12$, 13, 14. In patients 15 to 18 the cardiological findings were normal.

\section{Biochemical findings}

The following laboratory data were in the normal range in all 18 patients: cell blood count, blood urea, creatinine, sedimentation rate, $\mathrm{Ca}^{++}$and phosphate, electrolytes, total plasma proteins, protein electrophoresis, serum immunoglobulins, serum enzymes (alkaline and acid phosphatase, aldolase, creatine phospholinase, LDH, SGOT, SGPT). Bilirubin was normal except in patient 14 in whom a moderate increase of the total and unconjugated bilirubin was found. Serum lipoproteins, evaluated by an 
TABLE 1

Clinical Findings * In 18 Patients With The Presumptive Diagnosis Of Friedreich's Spinocerebellar Degeneration

\begin{tabular}{|c|c|c|c|c|c|c|c|c|c|c|c|c|c|c|}
\hline & Name & Sex & Age & $\begin{array}{c}\text { Age at } \\
\text { Onset }\end{array}$ & $\begin{array}{c}\text { Gait } \\
\text { Ataxia }\end{array}$ & $\underset{\text { Ataxia }}{\operatorname{Limb}}$ & $\begin{array}{l}\text { Nystag- } \\
\text { mus }\end{array}$ & Dysarthria & Areflexia & $\begin{array}{l}\text { Deep } \\
\text { Sensory } \\
\text { Loss }\end{array}$ & $\begin{array}{c}\text { Babinski } \\
\text { Sign }\end{array}$ & $\begin{array}{l}\text { Kypho- } \\
\text { scoliosis }\end{array}$ & $\begin{array}{c}\text { Pes } \\
\text { Cavus }\end{array}$ & $\begin{array}{c}\text { Cardio } \\
\text { Myopathy }\end{array}$ \\
\hline 1 & FD & $\mathrm{F}$ & 32 & 14 & + & + & + & + & + & + & + & + & + & + \\
\hline 2 & $\mathrm{ZG}$ & $\mathbf{M}$ & 32 & 15 & + & + & 0 & + & + & + & + & + & + & + \\
\hline 3 & FG & $\mathrm{F}$ & 28 & 14 & + & + & + & + & + & + & + & + & + & + \\
\hline 4 & $\mathrm{CP}$ & $\mathrm{F}$ & 21 & 8 & + & + & + & + & + & + & + & + & + & + \\
\hline 5 & SR & $\mathbf{M}$ & 14 & 2 & + & + & + & + & + & + & + & + & + & + \\
\hline 6 & PR & $\mathrm{F}$ & 15 & 6 & + & + & + & + & + & + & + & + & + & + \\
\hline 7 & $\mathrm{DA}$ & $\mathrm{F}$ & 19 & 11 & + & + & + & + & + & + & + & + & 0 & + \\
\hline 8 & $\mathrm{GM}$ & $F$ & 18 & 11 & + & + & + & + & + & + & + & + & + & + \\
\hline 9 & GB & $\mathrm{F}$ & 14 & 14 & 0 & \pm & 0 & 0 & + & \pm & + & \pm & + & + \\
\hline 10 & FA & $\mathbf{M}$ & 10 & 3 & + & + & 0 & + & + & + & + & + & + & + \\
\hline 11 & MA & $\mathrm{F}$ & 18 & 11 & + & + & + & + & + & + & + & + & + & + \\
\hline 12 & DG & $\mathbf{M}$ & 19 & 13 & + & + & + & + & + & + & + & + & + & + \\
\hline 13 & LI & $\mathrm{F}$ & 11 & 9 & + & + & 0 & + & + & + & 0 & + & + & + \\
\hline 14 & $\mathrm{RM}$ & $\mathbf{M}$ & 34 & 17 & + & + & 0 & + & 0 & + & + & \pm & 0 & + \\
\hline 15 & DM & $\mathbf{M}$ & 22 & 7 & * & * & 0 & + & + & 0 & + & + & + & 0 \\
\hline 16 & $\mathrm{DR}$ & $\mathbf{M}$ & 15 & 8 & + & + & 0 & + & 0 & 0 & + & \pm & + & 0 \\
\hline 17 & DI & $\mathrm{F}$ & 34 & 22 & + & \pm & + & + & + & + & 0 & 0 & 0 & 0 \\
\hline 18 & DW & F & 33 & 20 & + & \pm & + & + & + & + & 0 & 0 & + & 0 \\
\hline
\end{tabular}

* + indicates the presence of the sign. 0 its absence.

electrophoretic method not allowing quantitation of the single lipoprotein classes, were within normal range. The mean serum total cholesterol was 172 $\pm 32 \mathrm{mg} / \mathrm{dl}$ (range 139-245). These values are comparable to those of agematched controls in our country. The mean serum triglycerides were $88 \pm 28$ $\mathrm{mg} / \mathrm{dl}$ (45-171), a value significantly lower $(p<0.02)$ that of 21 agematched controls $(115 \pm 37)$. Glucose intolerance was shown by the standard oral glucose-loading test in patients 3 , 5 , and 6. Clinical and chemical diabetes was present in patients 1 and 2. Fasting plasma pyruvate averaged $0.83 \pm 0.21 \mathrm{mg} / \mathrm{dl}(0.34-1.30)$, a value not different from that of 21 agematched controls $(0.84 \pm 0.14)$. The glucose-pyruvate test showed in the patients pyruvate areas greater (mean $18.266 \pm 3.795$; range $14,200-26.530$ square $\mathrm{mm}$ ) than the mean areas of the controls (mean $12.710 \pm 3.510 \mathrm{SD}$; range 9.200-16.000). The pyruvate areas however, were significantly greater

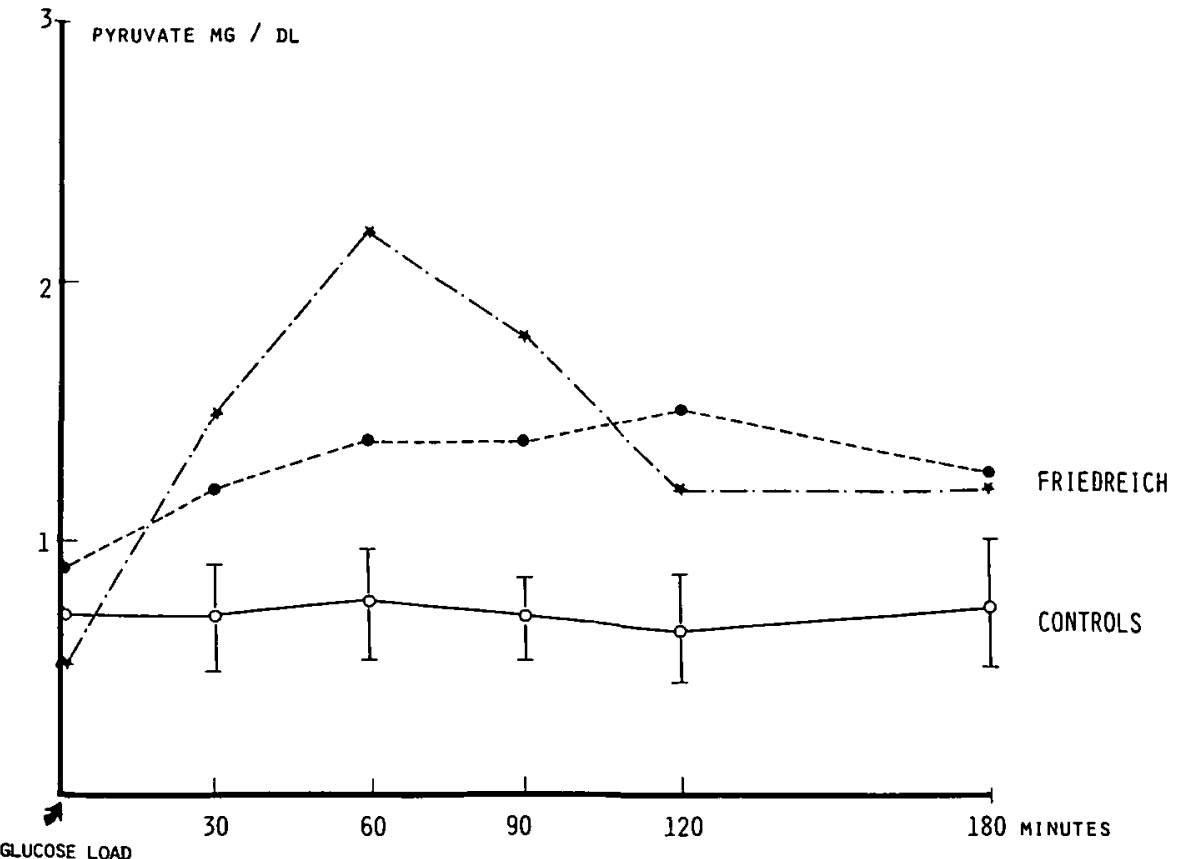

Figure 1 - Glucose pyruvate-test in controls and 2 Friedreich patients. Details concerning the methods are given in "Material and Methods". 
TABLE 2

Activities * of LAD In The Serum of F.A. Patients And Controls

\begin{tabular}{crr}
\hline Serum & Controls & \multicolumn{1}{c}{ Patients } \\
\hline $20 \mu \mathrm{l}$ & $9.55 \pm 1.81$ & $7.46 \pm 3.58$ \\
$40 \mu \mathrm{l}$ & $11.60 \pm 1.70$ & $10.00 \pm 3.80$ \\
\hline
\end{tabular}

* Activities are expressed in $U / 1 \pm S D$.

$(p<0.001)$ than those of the controls only in patients $1,2,4,6,8,11$ and 14 . In patients 15 to 18 pyruvate areas were close to those of controls. Typical glucose-pyruvate test in two positive F.A. patients and in controls are shown in fig. 1 . The activities of serum
LAD are seen in table 2: both with 20 and $40 \mu \mathrm{l}$ of serum, mean LAD activity was lower in F.A. patients than in controls. However, the values of LAD were more dispersed in the F.A. patients than in controls and the difference in activity between patients and controls was not statistically significant. The activity of arysulphatase $\mathrm{A}, \beta$-galactosidase and $\beta$-Nacetyl-glucosaminidase were determined in the leucocytes of the patients as previously described (Tettamanti et al, 1977) and proved to be within normal range. These enzyme activities are known to be decreased in genetic disorders associated with ataxia (McLeod et al, 1977; Pilz et al, 1977; Wengen et al, 1974).

\section{Neurophysiological findings}

The results of the electrophysiological study are summarized in table 3 . Spontaneous activity was present in 10 cases $(55,5 \%)$ : it mainly consisted of fibrillation on 1 d.i. (patients 8,13 ) or on d.i. and t.a. (patients $5,6,7,12,17$, 18). Rare fasciculations were also seen on the 1 d.i. (patients $2,5,8,9,13$ ); in patients 17 and 18 the fasciculation was more intense. In patient 18 pseudomyotonic discharges from t.a. were also recorded. Volitional activity was involved in 12 cases $(66,6 \%)$. Severe loss of motor units (single oscillation pattern) on maximal effort was present in 4 patients (brothers 15 and 16 and sisters 17 and 18 ) in all the tested muscles. A reduced innervation

TABLE 3

Neurophysiological Findings * In 18 Patients With Presumptive Diagnosis of Friedreich's Spinocerebellar Degeneration

\begin{tabular}{|c|c|c|c|c|c|c|c|c|c|c|c|}
\hline & & EMG & & & or Condu & tion Velo & & Sens & ry Action & otentials & \\
\hline & Spontaneous & & Volitional & & & Pero & al $n$. & Med & $\ln n$. & Sural & \\
\hline & & $\begin{array}{l}\text { Loss } \\
\text { of } \mathrm{MU}\end{array}$ & $\begin{array}{l}\text { Abnormal } \\
\text { MU param. }\end{array}$ & $\begin{array}{l}\text { Vel. } \\
\mathrm{m} / \mathrm{sec}\end{array}$ & $\begin{array}{c}\text { Dist. } \\
\text { lat. } \\
\text { m/sec }\end{array}$ & $\begin{array}{l}\text { Vel. } \\
\mathrm{m} / \mathrm{sec}\end{array}$ & $\begin{array}{l}\text { Dist. } \\
\text { lat. } \\
\text { m/sec }\end{array}$ & $\begin{array}{l}\text { Lat. } \\
\mathrm{m} / \mathrm{sec}\end{array}$ & $\underset{\mathbf{u V}}{\text { Ampl. }}$ & $\begin{array}{c}\text { Lat. } \\
\mathrm{m} / \mathrm{sec}\end{array}$ & $\underset{\text { uV }}{\text { Ampl. }}$ \\
\hline $1 \mathrm{FD}$ & 0 & 0 & 0 & 56 & 1.7 & 40 & 5.4 & 0 & 0 & 0 & 0 \\
\hline $2 \mathrm{ZG}$ & + & 0 & + & 48 & 2.2 & 43 & 5.6 & 0 & 0 & 0 & 0 \\
\hline $3 \mathrm{FG}$ & 0 & 0 & 0 & 55 & 2.2 & 33 & 3 & 0 & 0 & 0 & 0 \\
\hline $4 \mathrm{CP}$ & 0 & + & 0 & 51 & 2.1 & 43 & 3.8 & 3.6 & 4 & 0 & 0 \\
\hline $5 \mathrm{SR}$ & ++ & +t & 0 & 43 & 2.5 & 0 & $0^{* * *}$ & 0 & 0 & 0 & 0 \\
\hline $6 \mathrm{PR}$ & + & ++ & + & 54 & 1.9 & 34 & 3.6 & 0 & 0 & 0 & 0 \\
\hline $7 \mathrm{DA}$ & + & 0 & + & 48 & 2.4 & 39 & 4.7 & 0 & 0 & 0 & 0 \\
\hline $8 \mathrm{GM}$ & + & + & ++ & 43 & 2.5 & 37 & 5.3 & 0 & 0 & $\mathbf{0}$ & 0 \\
\hline $9 \mathrm{~GB}$ & + & + & ++ & 58 & 1.9 & 47 & 3.7 & 0 & 0 & 0 & 0 \\
\hline $10 \mathrm{FA}$ & 0 & ++ & 0 & 43 & 3 & 39 & 4.9 & 0 & 0 & 0 & 0 \\
\hline $11 \mathrm{MA}$ & 0 & + & + & 43 & 1.8 & 41 & 4.4 & 0 & 0 & 0 & 0 \\
\hline $12 \mathrm{DG}$ & ++ & 0 & + & 49 & 1.7 & 47 & 3.8 & 0 & 0 & 0 & 0 \\
\hline $13 \mathrm{LI}$ & + & 0 & + & 44 & 2 & 45 & 4.1 & 0 & 0 & 0 & 0 \\
\hline $14 \mathrm{RM}$ & 0 & + & + & 45 & 1.7 & 32 & 5.9 & 3.4 & 2.8 & 5.1 & 1.5 \\
\hline $15 \mathrm{DM}$ & 0 & t+t & ++ & 46 & 1.9 & 34 & 6.6 & 0 & 0 & 0 & 0 \\
\hline $16 \mathrm{DR}$ & 0 & t+t & t+ & 55 & 1.9 & 36 & 5.9 & 4.1 & 2.5 & 0 & 0 \\
\hline $17 \mathrm{DI}$ & +++ & +t+ & ++ & 48 & 4 & 37 & 5.2 & 0 & 0 & 0 & 0 \\
\hline $18 \mathrm{DW}$ & +++ & +++ & t+ & 34 & 1.6 & 38 & 9.8 & 0 & 0 & 0 & 0 \\
\hline Controls' & 0 & 0 & 0 & 60.2 & 2.48 & 52.7 & 3.01 & 3.1 & 16.3 & 3.3 & 21 \\
\hline mean valu & (170 age-matc & hed nor & al indiv) & SD 5.6 & SD 0.6 & SD 5.0 & SD 0.5 & SD 0.3 & SD 0.5 & SD 0.4 & SD 9 \\
\hline LIMIT V & LUE $* * * *$ & & & 51 & 3.5 & 44 & 3.8 & 3.6 & 8 & 4 & 6 \\
\hline
\end{tabular}

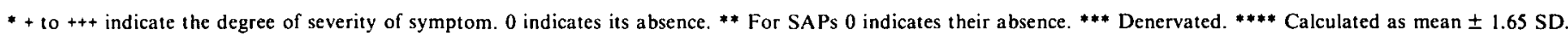


pattern confined to the lower limbs was found in 8 patients $(4,5,6,8,9,10$, $11,14)$. Partial loss of motor units in e.d.b. was considered paraphysiological (Wiechers et al, 1976). Severe involvement of this muscle when not accompanied by pes cavus (patients 14 and 17) was rated a major symptom. Increased amplitude was the main abnormality observed in motor unit action potential parameters sometimes associated with increased mean duration and percentage polyphasic potentials. These abnormalities were marked in both the upper and the lower limbs in the patients 8,9 and 15 to 18 : in seven patients $(2,6,7,11,12,13,14)$ they were of moderate degree and confined to the lower or to the upper limbs. A significant increase of polyphasic potentials $>50 \%$ ) was found in patients $7,8,12,13$ and 17 . Clear evidence of marked diffuse denervation with high probability of lower motor neuron involvement was present in patients $15,16,17,18$. Ulnar nerve maximal motor conduction velocity showed a mean value of $47.4 \mathrm{~m} / \mathrm{sec}$, $21 \%$ lower than the mean of controls with pathological values (lower than limit value, table 3 ) in 13 cases $(72,2 \%)$. Peroneal nerve mean maximal motor conduction velocity was 39.12 on 17 cases (36\% lower than controls). It was pathological in 14 cases $(77.71 \%)$. Total denervation of e.d.b. was observed in one case (n.5). VCMM was particularly low in patient 18 in the ulnar nerve and in patients 3,6 and 14,16 in the peroneal nerve. Distal latencies were increased over the control values) in 12 cases $(66,6 \%)$; this was particularly true for patients 14 , 15,16 and 18 . Sensory action potentials (SAP), measured with surface electrodes, were absent in the median nerve of all the patients except 4, 14 and 16 . Latency, however, was increased in the two latter patients. SAPs were absent in all the patients except patient 14 in the sural nerve. In this patient however, the latency was increased.

\section{DISCUSSION}

Geoffroy et al (1976) proposed strict clinical criteria for the diagnosis of "typical F.A." In their series of patients the rate of incidence for gait ataxia, progression without remission of ataxia, dysarthria, areflexia, deep sensory loss, muscle weakness was $100 \%$; pes cavus, Babinski sign and cardiomyopathy were found in $97 \%$ and kyphoscoliosis in $90 \%$ of the typical patients. "Incomplete typical F.A." meant that only pes cavus or Babinski signs were lacking whilst "atypical F.A." meant the absence of one or more of the major signs or symptoms (Geoffroy et al, 1976). Our patients 1 to 13 were broadly homogeneous on a clinical basis and would fall into the typical F.A. group of Geoffroy (patient 9 in whom clinical features were somewhat different from the other typical patients has been discussed in "Clinical findings"). Patient 14 had late onset and slow progression of the disease and was therefore different from patients 1 to 13 . However, he shared with these patients the hypertrophic obstructive cardiomyopathy, a sign considered typical of F.A. by several authors (Hewer, 1968; Pernot, 1979). On the other hand, patients 15 to 18 had no cardiac involvement. Moreover, they differed from patients 1 to 14 because they lacked several major findings typical of F.A. (such as deep sensory loss, Babinski sign, kyphoscoliosis) and had additional neurological symptoms (such as cramps and fasciculation). These patients were therefore suffering from a variant of F.A.: whether to include them in type Ila of Geoffroy (atypical F.A.), or in type IIb (non-Friedreich ataxia) is a problem because all these four patients shared with type IIa many signs and symptoms, but they lacked cardiomyopathy, a feature present in $100 \%$ of type Ila patients of Geoffroy et al (1976). The neurophysiological study showed in our patients 1 to 14 moderate abnormalities in volitional activity associated with slight spontaneous activity. Both these findings were mainly in the lower limbs. Loss of motor units was a major feature in patients 15 to 18 . Mean maximal motor conduction velocity (VCMM) in our 18 patients was reduced $(-21 \%$ on ulnar nerve, $-36 \%$ on peroneal nerve). In our typical patients (1 to 13) however, VCMM was reduced by $12 \%$ on average. These data are comparable with those found in F.A. by other investigators (McLeod, 1971; Peyronnard et al, 1976). VCMM was particularly decreased and distal latencies increased in the patients 14 , 15,16 and 18. SAP were absent in all but three patients; in these patients however, they were lower in amplitude than in controls (see table 3). Therefore mild abnormalities of the EMG pattern, slight reduction of the VCMM and absence or reduction in amplitude of the SAP seemed to be the neurophysiological pattern of typical F.A. (patients 1 to 13). Significantly, patients 15 to 18 with a variant of $F$.A. showed marked abnormalities of the volitional EMG activity particularly in the lower limbs and slight to moderate spontaneous activity in both the upper and lower limbs. Marked abnormalities of the VCMM and distal latencies in the lower limbs were additional features in these patients. Patient 14 had, on the peroneal nerve, lower VCMM and higher distal latencies than in patients 1 to 13 with typical F.A.; moreover his SAP were present though moderately. This patient suffered from a slow progressive form of F.A. reminiscent of the patients originally described by Roussy and Levy (1926). In 4 of these patients, clinical examination performed 20 years after the original description of Roussy and Levy showed the presence of deep sensory loss, kyphoscoliosis and Babinski sign (Lapresle, 1956). The neurophysiological findings in patient 9 was interesting: her pattern was similar, in the EMG abnormalities and SAP absence, to that found in typical F.A. patients. However, this young girl had not yet developed ataxia. This may suggest that simple neurophysiological studies could be a useful tool for predicting the disease in relatives of F.A. patients (McLeod, 1971). Biological data in our patients were confirmatory of other studies in that they revealed the presence of chemical and/or clinical diabetes in $28 \%$ of patients (Shapcott et al, 1976; Thoren, 1962). Lipid studies were different from those of other investigators in that they showed normal serum cholesterol and low triglycerides (Butterworth et al, 1976; Welker et al, 1980). However, we do not stress this latter finding because serum triglyceride values vary with diet. This may be different in normal populations and in markedly diseased people. 
Bilirubin was abnormal only in one of our patients at variance with the data reported by Barbeau (1979). By contrast, we confirmed the data of Barbeau et al (1976) on the abnormalities of the glucose pyruvate test: $40 \%$ of our patients had pyruvate areas significantly higher than controls. In none of the 4 patients with atypical F.A. was the pyruvate areas significantly increased. In 12 patients with typical F.A. (1 to 8, 10 to 13 ), mean serum LAD activity was, as reported by Filla et al (1978), lower than in controls; the difference, however, was not statistically significant. The cardiological findings in our study were positive in 14 of the 18 patients and were, for most of them, conclusive for hypertrophic cardiomyopathy mainly affecting the right ventricle. From our data it may be concluded that patients with "pure" or "typical" F.A. were characterized by onset of the symptoms in childhood with gait and limb ataxia, dysarthria, posterior column signs, kyphoscoliosis, reduction or absence of tendon reflexes and signs and symptoms of cardiomyopathy; Babinski and pes cavus were almost always present. Neurophysiology gave additional substance to the diagnosis of typical F.A. by showing an association of EMG, VCMM and SAP abnormalities. This pattern differs considerably from that found in hereditary hypertrophic sensory motor neuropathies, in which signs of peripheral motor neuron involvement were the major findings (Dick and Lambert, 1968a; 1971). However, the neurophysiological abnormalities found in our F.A. patients were shared by the patients with the neural form of hereditary sensory-motor neuropathies (Dick and Lambert, 1978b). Biochemical abnormalities which could be identified with routine laboratory studies were restricted in our study to glucose and pyruvate metabolism; moreover these abnormalities were not present in all the typical F.A. patients. Therefore, neither neurophysiological nor the biochemical data can per se identify typical F.A. patients. Moreover, these abnormalities were not correlated in our study with the age or clinical stage. The availability of a biochemical marker of F.A. is still lacking and we believe that research must be supported in order to reach this goal. As the disease is genetic, the use of cultured cells from the patients seems to be highly desirable.

\section{EDITOR'S NOTE}

The above paper is the same text which has been accepted for publication in the Italian Journal of Neurological Sciences (September 1980) and is reproduced here with the express permission of the IJNS editor and the authors because of its pertinence to the Quebec Cooperative Study on Friedreich's Ataxia.

\section{REFERENCES}

BARBEAU, A. (1976). Quebec cooperative study of F.A.: design of the investigation. Can. J. Neurol. Sci. 3: 271-274.

BARBEAU, A., BUTTERWORTH, R.F., NGO, T., BRETON, G., MELANCYON, S., SHAPCOTT, D., GEOFFROY, G. and LEMIEUX, B. (1976). Pyruvate metabolism in Friedreich's ataxia. Can. J. Neurol. Sci. 3: 379-388.

BARBEAU, A. (1978). Cooperative study: Phase two. Statement of the problems. Can. J. Neurol. Sci. 5: 57-59.

BARBEAU, A. (1979). Friedreich's ataxia 1979: an overview. Can. J. Neurol. Sci. 6: 311-319.

BLASS, J.P., AVIGAN, J. and UHLENDORF, B.W. (1970). A defect in pyruvate decarboxylase in a child with intermittent movement disorder. J. Clin. Invest. 49: 423-432.

BLASS, J.P., KARK, P.R.A. and MARION, N.K. (1976). Low activities of the pyruvate and oxoglutarate dehydrogenase complexes in five patients with Friedreich's ataxia. New Engl. J. Med. 8: 62-67.

BUTTERWORTH, R.F., SHAPCOTT, D., MELANCCON, S., BRETON, G., GEOFFROY, G., LEMIEUX, B. and BARBEAU, A. (1976). Clinical laboratory findings in Friedreich's ataxia. Can. J. Neurol. Sci. 3: 355-358.

DICK, P.J. and LAMBERT, E.H. (1968a). Lower motor and primary sensory neuron diseases with peroneal muscular atrophy. $\mathrm{I}^{\circ}$ neurologic genetic and electrophysiologic findings in hereditary polyneuropathies. Arch. Neurol. 18: 603-618.

DICK, P.J. and LAMBERT, E.H. (1968b). Lower motor and primary neuron diseases with peroneal muscular atrophy. $\mathrm{II}^{\circ}$ neurologic genetic and electrophysiologic findings in various neuroneal degeneration. Arch. Neurol. 18: 619-625.

DICK, P.J., LAMBERT, E.H., SANDERS, K. and O'BRIEN, P.C. (1971). Severe hypomyelination and marked abnormality of conduction in Déjerine-Sottas hypertrophic neuropathy: myelin and compound action potential of sural nerve in vitro. Mayo Clinic Proc. 46: 432-440.

DI DONATO, S., CORNELIO, F., BALESTRINI, M.B., BERTAGNOLIO, B. and PELUCHETTI, D. (1978). Mitochondrialipid-glycogen myopathy, hyperlactacidemia and carnitine deficiency. Neurology 28: $1110-1116$.
FILLA, A., BUTTERWORTH, R.F., GEOFFROY, G., LEMIEUX, B. and BARBEAU, A. (1978). Serum and platelet lipoamide dehydrogenase in Friedreich's ataxia. Can. J. Neurol. Sci. 5: 111-114.

GEOFFROY, G., BARBEAU, A., BRETON, G., LEMIEUX, B., AUBE, M., LEGER, C. and BOUCHARD, J.P. (1976). Clinical description and roentgenologic evaluation of patients with F.A. Can. J. Neurol. Sci. 4: 279.

HEWER, R.L. (1968). Study of fatal cases of Friedreich's ataxia. Brit. Med. J. 3: 649-652.

HUANG, Y.S., NESTRUCK, A.C., BARBEAU, A., BOUCHARD, J.P. and DAVIGNON, J. (1978). Plasma lipids and lipoproteins in Friedreich's ataxia and familial spastic ataxia. Evidence for an abnormal composition of high density lipoproteins. Can. J. Neurol. Sci. 5: 149-156.

KARK, P.R.A., BLASS, J.P. and ENGEL, W.K. (1974). Pyruvate oxidation in neuromuscular diseases. Neurology 24: 864-871.

KARK, P.R.A. and RODRIQUEZ-BUDELLI, M. (1979). Pyruvate dehydrogenase deficiency in spinocerebellar degenerations. Neurology 29: $126-131$.

LAPRESLE, J. (1956). Contribution à l'étude de la Dystasie aréflexique héréditaire. Etat actuel de quatre des sept cas princeps de Roussy et Mlle Levy, trente années après la première publication de ces auteurs. Sem Hôp Paris 32: 2473-2482.

McLEOD, J.G. (1971). An electrophysiological and pathological study of peripheral nerves in Friedreich's ataxia. J. Neurol. Sci. 12: 333349.

McLEOD, P.M., WOOD, S. and JEAN, J.E. (1977). Progressive cerebellar ataxia, spasticity psychomotor retardation and hexosaminidase deficiency in a 10-year-old child. Juvenile Sandhoff disease. Neurology 27: 571-573.

OPPENHEIMER, D.R. (1958). Diseases of the basal ganglia, cerebellar and motor neurons in Greenfield's Neuropathology, Blackwood W, Corsellis JAN (Eds) Arnold E. Publ., London pp 608-651.

PELLEY, J.W., GWINNE, H.L., LINN, T.C. and HELL, F.F. (1962). Lipoamide dehydrogenase in serum: a preliminary report. Clin. Chem. 22: 275-276.

PERNOT, C. (1979). La myocardiopathie de la maladie de Friedreich. Arch. Franç. Pédiat. 36: $11-18$.

PEYRONNARD, J.M., BOUCHARD, J.P., LAPOINTE, L., LAMONTAGNE, A., LEMIEUX, B. and BARBEAU, A. (1976). Nerve conduction studies and electromyography in Friedreich's ataxia. Can. J. Neurol. Sci. 3: 313-318.

PHILZ, H., DUENSING, I. and HEIPERTZ, R. (1977). Adult metachromatic leukodystrophy. Europ. Neurol. 15: 301-307.

ROUSSY, G. and LEVY, G. (1926). Sept cas d'une maladie familiale particulière: troubles de la marche, pieds bots et aréflexie heudireuse généralisée avec accessoirement, légère maladresse des mains. Rev. Neurol. 1: 427-450.

SHAPCOTT, D., MELANCYON, S.B., BUT- 
TERWORTH, R.F., KHOURY, K., COLLU, R., BRETON, G., GEOFFROY, G., LEMIEUX, B. and BARBEAU, A. (1976). Glucose and insulin metabolism in Friedreich's ataxia. Can. J. Neurol. Sci. 3: 361364.

TETTAMANTI, G., LOMBARDO, A., MARCHESINI, A., BERRA, B., DI DONATO, S., RIMOLDI, M. and BERTAGNOLIO, B. (1977). Lipid storage diseases: biochemical diagnosis. Biochem. Exp. Biol. XIII: 45-62.
THOREN, C. (1962). Diabetes mellitus in Friedreich's ataxia. Acta Pediat. Suppl. 135: 233.

TYRER, J.H. (1975). Friedreich's ataxia; in: Handbook of Clinical Neurology Vol. 21 (Vinken, P.J. and Bruyn, G.W. eds.) North Holland Publ. Co. Amsterdam pp 319-364.

WELKER, J.L., CHAMBERLAIN, S. and ROBINSON, N. (1980). Lipids and lipoproteins in Friedreich's ataxia. J. Neurol. Neurosurg. Psych. 43: 111-117.
WENGEN, D.A.. GOODMAN, S.I. and MYERS, G.G. (1974). B-Galactosidase deficiency in young adults. Lancet 2: 1319.

WIECHERS, D., GUYTON, J.D. and JOHNSON, E.W. (1976). Electromyographic findings in the extensor digitorum brevis in a normal population. Arch. Physical Med. and Rehabilitation 57: 84-85.

WILLIAMS, L.L. (1979). Pyruvate oxidation in Charcot-Marie-Tooth disease. Neurology 29: 1492-1498. 